\title{
Neurochemical Alterations in Methamphetamine-Dependent Patients Treated with Cytidine-5'-Diphosphate Choline: A Longitudinal Proton Magnetic Resonance Spectroscopy Study
}

\author{
Sujung J Yoon', In Kyoon Lyoo*,2,3, Hengjun J Kim³, Tae-Suk Kim', Young Hoon Sung,5, Namkug Kim ${ }^{4,5}$, \\ Scott E Lukas ${ }^{2,6}$ and Perry F Renshaw ${ }^{4,5}$ \\ 'Department of Psychiatry, Catholic University of Korea School of Medicine, Seoul, South Korea; 'Department of Psychiatry, Harvard Medical \\ School, Boston, MA, USA; ${ }^{3}$ Brain Imaging Center and Clinical Research Center, Seoul National University Hospital, Seoul, South Korea; \\ ${ }^{4}$ Department of Psychiatry and The Brain Institute, University of Utah, SLC, UT, USA; ${ }^{5}$ Department of Veterans Affairs VISN 19 MIRECC, SLC, UT, \\ USA; ${ }^{6}$ McLean Hospital Brain Imaging Center, Belmont, MA, USA
}

\begin{abstract}
Cytidine-5'-diphosphate choline (CDP-choline), as an important intermediate for major membrane phospholipids, may exert neuroprotective effects in various neurodegenerative disorders. This longitudinal proton magnetic resonance spectroscopy $\left({ }^{\prime} \mathrm{H}-\mathrm{MRS}\right)$ study aimed to examine whether a 4-week CDP-choline treatment could alter neurometabolite levels in patients with methamphetamine (MA) dependence and to investigate whether changes in neurometabolite levels would be associated with MA use. We hypothesized that the prefrontal levels of N-acetyl-aspartate (NAA), a neuronal marker, and choline-containing compound (Cho), which are related to membrane turnover, would increase with CDP-choline treatment in MA-dependent patients. We further hypothesized that this increase would correlate with the total number of negative urine results. Thirty-one treatment seekers with MA dependence were randomly assigned to receive CDP-choline $(n=16)$ or placebo $(n=15)$ for 4 weeks. Prefrontal NAA and Cho levels were examined using 'H-MRS before medication, and at 2 and 4 weeks after treatment. Generalized estimating equation regression analyses showed that the rate of change in prefrontal NAA $(p=0.005)$ and Cho $(p=0.03)$ levels were greater with CDP-choline treatment than with placebo. In the CDP-choline-treated patients, changes in prefrontal NAA levels were positively associated with the total number of negative urine results $(p=0.03)$. Changes in the prefrontal Cho levels, however, were not associated with the total number of negative urine results. These preliminary findings suggest that CDP-choline treatment may exert potential neuroprotective effects directly or indirectly because of reductions in drug use by the MA-dependent patients. Further studies with a larger sample size of MA-dependent patients are warranted to confirm a long-term efficacy of CDP-choline in neuroprotection and abstinence.

Neuropsychopharmacology (20 10) 35, I |65-I I73; doi:I 0.1038/npp.2009.22 I; published online 30 December 2009
\end{abstract}

Keywords: cytidine-5'-diphosphate choline; methamphetamine dependence; N-acetyl-aspartate; treatment; proton magnetic resonance spectroscopy

\section{INTRODUCTION}

Methamphetamine (MA) is a highly addictive drug and its dependence has become a critical public health problem (Meredith et al, 2005). Although its usage is not as prevalent as that of cocaine, MA is the fastest growing street drug in the United States (Drug Enforcement Administration, 2008). It has been estimated that 10.4 million or $4.3 \%$ of the US population have used MA at some time in their lives (National Survey on Drug Use and Health, 2005).

*Correspondence: Dr IK Lyoo, Departments of Psychiatry and Neuroscience, Seoul National University College of Medicine, 28 Yongon-dong, Chongro-gu, Seoul I I0-744, South Korea, Tel: + 822 2072 2302, Fax: + 8223672 0677, E-mail: inkylyoo@snu.ac.kr Received 7 June 2009; revised 8 October 2009; accepted 5 November 2009
Psychosocial and behavioral approaches have been shown to provide therapeutic and beneficial effects and are currently considered as primary treatment modalities in patients with MA dependence (Lee and Rawson, 2008; Meredith et al, 2005; Shearer, 2007). Despite efforts to develop or discover medications for psychostimulant dependence, there have not been any Food and Drug Administration-approved pharmacotherapies (Meredith et al, 2005; Rawson et al, 2000; Vocci and Appel, 2007). MA has neurotoxic effects and can cause cognitive impairment (Davidson et al, 2001; Scott et al, 2007). This, in turn, may act as a potential barrier for MA-dependent subjects receiving the benefits from cognitive behavioral therapy (CBT) (Grohman et al, 2006; Meredith et al, 2005). Development of an effective pharmacotherapy that decreases MA use and potentially improves cognitive function 
would, therefore, be an important strategy in treating MA dependence (Meredith et al, 2005; Vocci and Appel, 2007).

Cytidine-5'-diphosphate choline (CDP-choline) is an essential intermediate in the biosynthesis pathway of structural phospholipids of cell membranes (Kennedy and Weiss, 1956; Secades and Lorenzo, 2006). The formation of CDP-choline from phosphocholine (PC) has been considered to regulate, as a rate-limiting step, the synthesis of phosphatidylcholine, a major constituent of cell membranes (Araki and Wurtman, 1998; Clement and Kent, 1999). When CDP-choline is administered orally or intravenously, it activates the biosynthesis of structural phospholipids in neuronal membranes (Adibhatla and Hatcher, 2005; Secades and Lorenzo, 2006). CDP-choline has been shown to increase cerebral energy metabolism by restoring the activity of mitochondrial ATPase and membrane $\mathrm{NA}+/ \mathrm{K}+$ ATPase (Secades and Lorenzo, 2006).

Psychostimulant abuse, including cocaine and MA, causes acute and chronic complications related to cerebrovascular spasm or ischemic brain damage (Wang et al, 1990). There has been a substantial amount of in vitro evidence that CDP-choline has neuroprotective effects against hypoxic or ischemic brain damage by restoring neuronal activity and re-stabilizing dopamine and norepinephrine levels (reviewed in Secades and Lorenzo, 2006). In addition, it has been suggested that the neuroprotective effects of CDPcholine may be related to a direct anti-apoptotic mechanism (Barrachina et al, 2002).

In addition to the actions of psychostimulants on mesolimbic and mesocortical dopamine circuitry (Berman et al, 2008), recent preclinical and clinical studies suggest that these drugs may cause alterations in phospholipid metabolism (Reid et al, 1996; Ross et al, 1996, 2002; Ross and Turenne, 2002). Dopaminergic receptor-mediated phospholipase A2 activation and increased phospholipid hydrolysis has also been suggested by in vitro studies (Hussain and Lokhandwala, 1997; McAllister et al, 1993; Vial and Piomelli, 1995). Phosphorous magnetic resonance spectroscopy (MRS) studies have reported that cocainedependent polysubstance abusers have lower cerebral levels of phosphomonoester and phosphodiester. This is likely to reflect altered membrane phospholipid turnover (Christensen et al, 1996; MacKay et al, 1993).

Proton MRS studies have consistently reported lower cerebral $\mathrm{N}$-acetyl-aspartate (NAA) levels, a marker of neuronal integrity and density, in MA-dependent subjects (Chang et al, 2005; Ernst et al, 2000; Nordahl et al, 2002, 2005; Salo et al, 2007; Smith et al, 2001; Sung et al, 2007). Altered cerebral levels of a choline-containing compound (Cho), consisting of PC and glycerophosphocholine (GPC) (Bluml et al, 1999), have also been observed in most MAdependent patients (Chang et al, 2005; Ernst et al, 2000; Nordahl et al, 2002, 2005; Salo et al, 2007). Considering that PC and GPC are products of synthesis and breakdown, respectively, of cerebral membranes (Babb et al, 2002; Silveri et al, 2008), lower NAA levels along with altered Cho signals in MA-dependent patients suggest that chronic MA exposure causes neuronal loss with accelerated membrane turnover (Deicken et al, 1998; Winsberg et al, 2000).

Oral CDP-choline administration has the ability to increase the membrane production of neurons and has been proposed as a potential treatment option for psychostimulant dependence (Brown et al, 2007; Lukas et al, 2001; Renshaw et al, 1999). CDP-choline has been shown to be effective in attenuating craving and improving cognitive function in cocaine-dependent patients (Brown et al, 2007; Lukas et al, 2001; Renshaw et al, 1999). To the best of our knowledge, there has not been any study examining the neurochemical and clinical effects of CDPcholine in treating MA-dependent patients.

This longitudinal proton MRS ( $\left.{ }^{1} \mathrm{H}-\mathrm{MRS}\right)$ study aimed to assess whether oral CDP-choline administration is associated with changes in prefrontal NAA and Cho levels and whether these changes are related to clinical improvement.

\section{MATERIALS AND METHODS}

\section{Subjects}

All study participants, aged 20-59 years, met the DSM-IV criteria for MA dependence and were seeking treatment for their MA dependence. All subjects were native Koreans. They reported that they had been using MA for at least 1 month before enrollment. Mean durations of illness of all subjects were 13.8 years. MA may be taken orally, intranasally, by smoking or intravenous (IV) injection. In South Korea, most MA abusers prefer IV injections. All participants in the study reported that IV injection was the primary route of administration. The comorbid substance dependence or abuse histories of participants are presented in Table 1.

We excluded individuals with DSM-IV diagnosed abuse or dependence on any psychoactive substances other than MA, nicotine, alcohol, or marijuana. Those with current major medical disorders, neurological disorders, or comorbid Axis I or II psychiatric disorders were also excluded. Having a past or current history of taking concomitant psychoactive medication was another exclusion criteria. Pregnant women were excluded and women with child bearing potential were required to use effective contraception methods. Contraindications to magnetic resonance imaging (MRI) and a history of seropositive testing for human immunodeficiency virus were also the exclusion criteria.

Before participating in the study, and after being thoroughly instructed of its description, each subject submitted a written informed consent. Both the study protocol and consent form received ethics approval from the Institutional Review Board at St Paul's Hospital, Catholic University of Korea School of Medicine.

\section{Study Design and Treatment Schedule}

This study was a 4 -week, double-blind, placebo-controlled study examining the neurochemical effects and the efficacy of CDP-choline in MA-dependent subjects. Each participant's drug-use history was obtained at a screening period using the semi-structured interview. This format has been used in our prior imaging studies on MA dependence (Bae et al, 2006; Chung et al, 2007; Hwang et al, 2006; Kim et al, 2005, 2006; Sung et al, 2007). Psychiatric diagnosis was determined using the Structured Clinical Interview for DSM-IV (First et al, 2002). Physical health was assessed by way of a physical examination and laboratory studies. 
Table I Demographic and Clinical Characteristics of 3 I Patients with Methamphetamine-Dependence Treated with CDP-choline or Placebo

\begin{tabular}{|c|c|c|c|}
\hline & $\begin{array}{l}\text { CDP-choline } \\
\text { group } \\
(n=16)\end{array}$ & $\begin{array}{l}\text { Placebo } \\
\text { group } \\
(n=15)\end{array}$ & $p$-value \\
\hline Age (years), mean $\pm S D$ & $38.6 \pm 3.9$ & $38.3 \pm 3.5$ & 0.79 \\
\hline Male, n (\%) & $12(75.0)$ & II (73.3) & 0.62 \\
\hline Right handedness, n (\%) & $14(87.5)$ & $13(86.7)$ & 0.68 \\
\hline Education (years), mean $\pm \mathrm{SD}$ & $10.9 \pm 1.6$ & $10.7 \pm 1.6$ & 0.81 \\
\hline $\begin{array}{l}\text { Age at onset of MA use (years), } \\
\text { mean } \pm S D\end{array}$ & $24.8 \pm 6.2$ & $24.5 \pm 5.7$ & 0.87 \\
\hline $\begin{array}{l}\text { Duration of MA use (months), } \\
\text { mean } \pm \text { SD }\end{array}$ & $13.8 \pm 6.5$ & $13.8 \pm 6.7$ & 0.99 \\
\hline \multicolumn{4}{|l|}{ Route of MA administration } \\
\hline Intravenous injection, $n$ (\%) & $16(100)$ & $15(100)$ & - \\
\hline Average daily dose $(\mathrm{g})$, mean $\pm \mathrm{SD}$ & $0.58 \pm 0.42$ & $0.44 \pm 0.33$ & 0.32 \\
\hline \multicolumn{4}{|l|}{ Alcohol use, $n$ (\%) } \\
\hline Current alcohol abuse & $2(12.5)$ & $3(20.0)$ & - \\
\hline Past history of alcohol dependence & I (6.3) & $2(13.3)$ & \\
\hline \multicolumn{4}{|l|}{ Marihuana use, $n$ (\%) } \\
\hline $\begin{array}{l}\text { Current marihuana abuse or } \\
\text { dependence }\end{array}$ & $5(31.2)$ & $5(33.3)$ & - \\
\hline Smoking (pack year), mean \pm SD & $13.7 \pm 6.8$ & $12.4 \pm 8.9$ & 0.67 \\
\hline Baseline HDRS scores, mean \pm SD & $12.3 \pm 7.5$ & $13.6 \pm 5.3$ & 0.57 \\
\hline
\end{tabular}

Abbreviations: CDP-choline, cytidine-5'-diphosphate choline; MA, methamphetamine; HDRS, Hamilton Depression Rating Scale.

Among the initially enrolled 32 treatment-seeking subjects with MA dependence, one male patient retracted his consent before randomization. A total of 31 patients with MA dependence were randomly assigned to receive $2 \mathrm{~g}$ /day of CDP-choline $(n=16)$ or placebo $(n=15)$, respectively (see Table 1).

All randomized subjects provided three urine samples during a 1-week baseline period. The 17-item Hamilton Depression Rating Scale (HDRS, Hamilton, 1960) was also used to assess the current depressive symptoms at baseline.

After a 1-week baseline period, patients received a 4-week double-blind treatment of either CDP-choline or placebo. CDP-choline and identical placebo capsules were manufactured and provided by the Grupo-Ferre. (Barcelona, Spain). Each capsule contained $500 \mathrm{mg}$ of CDP-choline. Patients took two capsules twice daily (total $2 \mathrm{~g} /$ day). This particular dose has been used safely in treating other neurological disorders (Clark et al, 2001; Secades and Lorenzo, 2006). The regimen for the first week was $500 \mathrm{mg}$ CDP-choline twice daily followed by $1 \mathrm{~g}$ CDP-choline twice daily for the remaining treatment period. The placebo was formulated as an inert fructose pill.

All participants attended the outpatient clinic thrice weekly. On each visit during the 4-week treatment period, the subjects participated in a supervised urine sample process. The urine samples were screened for MA and its metabolites on each of these occasions. Missing samples were considered as positive results. The negative results were counted to examine their relationship with prefrontal neurometabolite level changes. HDRS scores and side effects were assessed weekly.

Usual outpatient-based supportive care, including individual and family counseling, was given to all participants on a weekly basis. The counseling was not specific for drug dependence.

Measurements of neurometabolites using ${ }^{1} \mathrm{H}$-MRS were conducted at baseline and 2 and 4 weeks after treatment.

\section{MRI/MRS Acquisition and Processing}

MRI was performed using a 3.0 Tesla General Electric whole body imaging system (GE VH/i). Sagittal T-1-weighted images (echo time $(\mathrm{TE})=14 \mathrm{~ms}$, repetition time $(\mathrm{TR})=5.7 \mathrm{~ms}, \quad 256 \times 256$ matrix, field of view $(\mathrm{FOV})=22 \mathrm{~cm}$, flip angle $=20^{\circ}$, number of excitation $(\mathrm{NEX})=1$, and slice thickness $/$ skip $=0.7 / 0 \mathrm{~mm}$ ) were obtained using a three-dimensional spoiled gradient echo pulse sequence. Axial T-2-weighted images $(\mathrm{TE}=118 \mathrm{~ms}$, $\mathrm{TR}=3500 \mathrm{~ms}, 256 \times 192$ matrix, $\mathrm{FOV}=22 \mathrm{~cm}$, flip angle $=90^{\circ}, \mathrm{NEX}=3$, and slice thickness $/$ skip $=5 / 1.5 \mathrm{~mm}$ ) and fluid attenuated inversion recovery axial images $(\mathrm{TE}=145 \mathrm{~ms}, \quad \mathrm{TR}=9900 \mathrm{~ms}, \quad 256 \times 192$ matrix, $\mathrm{FOV}=$ $22 \mathrm{~cm}$, flip angle $=90^{\circ}, \mathrm{NEX}=1$, and slice thickness/ skip $=5 / 1.5 \mathrm{~mm}$ ) were obtained to screen for brain structural abnormalities.

Spectral data were obtained by using a water-suppressed, localized point resolved spectroscopy (PRESS) pulse sequence with a quadrature head coil. The parameters were as follows: $\mathrm{TR} / \mathrm{TE}=2000 / 35 \mathrm{~ms}$, phase cycling $=8$, voxel of interest $\quad(\mathrm{VOI})=15 \times 15 \times 15 \mathrm{~mm}^{3}$, acquisition time$128 \times 2 \mathrm{~s}$, and bandwidth $=2500 \mathrm{~Hz}$.

The midfrontal VOI was positioned by using a priori rules, as in earlier publications (Ham et al, 2007; Sung et al, 2007; Yoon et al, 2009) (Figure 1). Throughout the entire study period, the same examiner positioned study subjects in the basis set and reported as mmol/l (Provencher, 2001; Barker et al, 1993). An unsuppressed water signal was used as an internal concentration reference. The macromolecule and lipid basis spectra were also included in the LCModel fitting (Provencher, 2008).

Signal-to-noise ratio (SNR) and a full width at half maximum (FWHM) of each spectra were checked for quality control. Spectra quality was adequate for reliable peak fitting for metabolites, with mean SNR (SD) of 7.09 (1.25) and mean FWHM of 0.065 (0.013) ppm across every time point. We also considered metabolite concentrations from spectra with a Cramer-Rao Lower Bound value $>20 \%$ as unreliable (Provencher, 2001) and excluded them from the final analyses. Estimates of the variances associated with the metabolites were all in the acceptable range (within $20 \%$ ), except for myo-inositol resonances from one '2-week' follow-up scan (26\%) and one '4-week' follow-up scan (29\%). These myo-inositol estimations were excluded because of their poor reliability of determination.

Cerebrospinal fluid (CSF)-corrected metabolite concentrations were used in the analyses based on the assumption of metabolite concentration of zero in CSF (Bustillo et al, 2008; McLean et al, 2001). 
a

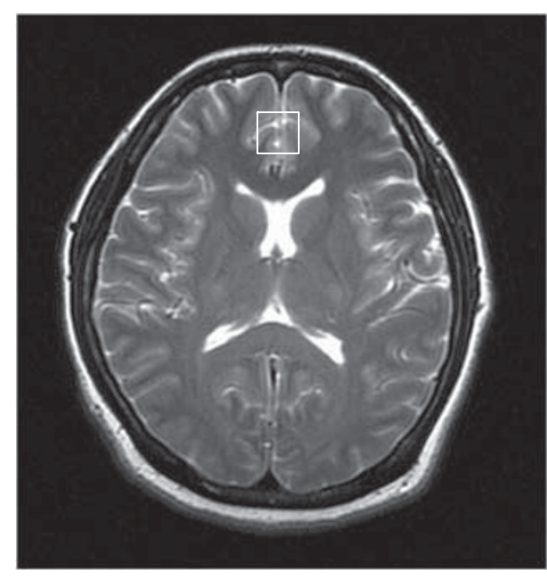

b

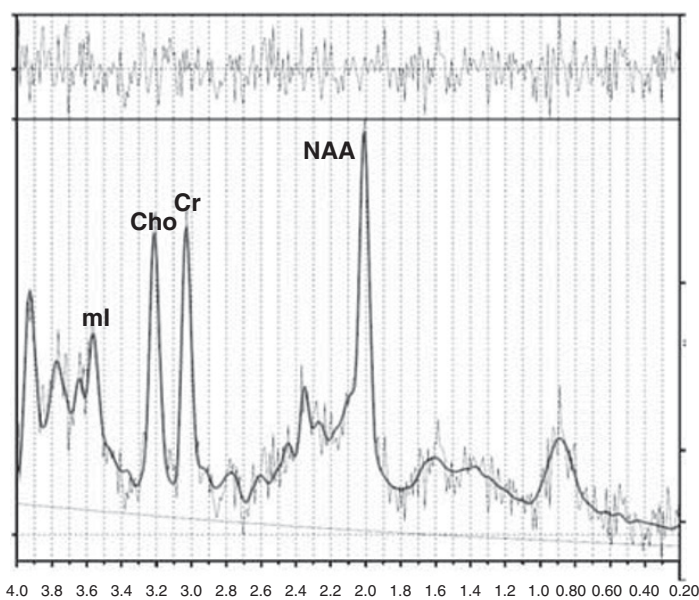

Chemical Shift (ppm)

Figure I Voxel placement (a) and representative spectra of a methamphetamine-dependent patient (b). (a) Typical location of voxel (white box) located on the midfrontal gray matter shown in axial T2-weighted magnetic resonance image. (b) Representative proton magnetic resonance spectra of one methamphetamine-dependent patients. LCModel estimated baselines are in smooth gray line. LCModel fit to metabolite signals are in red heavy line. The raw data is in thin gray trace. At the top of each plot, the residual signal after fitting is displayed. NAA, N-acetyl-aspartate/ $/ \mathrm{N}$-acetyl-aspartyl glutamate; Cr, creatine/phosphocreatine; Cho, phosphocholine/glycerophosphocholine; ml, myo-inositol.

\section{Statistical Analysis}

Baseline clinical characteristics and drug-use patterns involving continuous and categorical variables were analyzed using independent $t$-tests and $\chi^{2}$ tests, respectively. Fisher's exact test was used when the cell in the contingency table of categorical variables was sparse.

Generalized estimating equations (GEE) regression analysis models for continuous-dependent variables were adopted to analyze changes in prefrontal NAA and Cho levels and HDRS scores using all available data at each time point (Zeger and Liang, 1986). Age, sex, depression severity, and neurometabolite levels at baseline were covaried when necessary.

The total number of negative urine results was compared between the CDP-choline and placebo groups using independent $t$-tests. Spearman's correlation analyses were conducted to assess the relationship between changes in prefrontal NAA or Cho levels and the number of negative urine results.

Statistical significance was defined at an $\alpha$ level of $<0.05$ and two-tailed test. Stata 5.0 for Windows was used for all computations.

\section{RESULTS}

\section{Characteristics of Study Subjects}

There were no significant differences in demographic and clinical characteristics between the CDP-choline and placebo-treated MA-dependent subjects (Table 1).

Among the 31 patients who enrolled, 12 subjects (75.0\%) of the CDP-choline group and 9 subjects $(60.0 \%)$ of the placebo group completed the 4 -week treatment study. Two subjects dropped out of the study at week 1 , two at week 2 , five at week 3 , and one at week 4 . Subjects were requested to submit urine sample three times per week for the 4-week period (total possible screens $=12$ ). All subjects successfully submitted the urine samples each time they visited the outpatient clinic. Among all intent-to-treat subjects $(n=31)$ including 10 drop-outers, the mean number of urine samples submitted was 9.3 (SD, 3.3) and 7.9 (SD, 3.3) in the CDP-choline and placebo-treated groups, respectively. For 21 study completers who were retained in the study throughout the 4-week period, they were 10.9 (SD, 1.0) and 10.2 (SD, 1.3) in the CDP-choline and placebo-treated groups, respectively. There was no group difference in the number of submitted urine samples (for all subjects, $t=1.17, p=0.25$; for study completers, $t=1.39, p=0.18$ ). The treatment completion rate did not differ between the CDP-choline and placebo groups $(p=0.31)$. GEE model for weekly HDRS score changes did not show any significant group effect $(z=-0.53, p=0.60)$ or interaction effect $(z=0.09, p=0.93)$.

\section{Neurometabolite Measures}

There were no differences in gray matter, white matter, and CSF proportions of the VOI at each time point, between the CDP-choline and placebo groups.

There was a significant interaction effect of 'treatment group' and 'time' on changes in prefrontal NAA levels $(z=2.79, p=0.005)$. Prefrontal NAA levels increased steadily in the CDP-choline group (mean percentage change during the study period, 6.05\%), whereas those in the placebo group did not change over the same period (mean percentage change during the study period, $-1.16 \%$ ) (Figure 2). Changes in prefrontal Cho levels showed a similar pattern. The CDP-choline group (mean percent change during the study period, 3.05\%) had a greater increase in prefrontal Cho levels during the 4-week treatment period than the placebo group (mean percent change during the study period, $-0.61 \%)(z=2.13, p=0.03$; Figure 2).

The results remained unchanged when alcohol or marijuana abuse status was included as an additional 

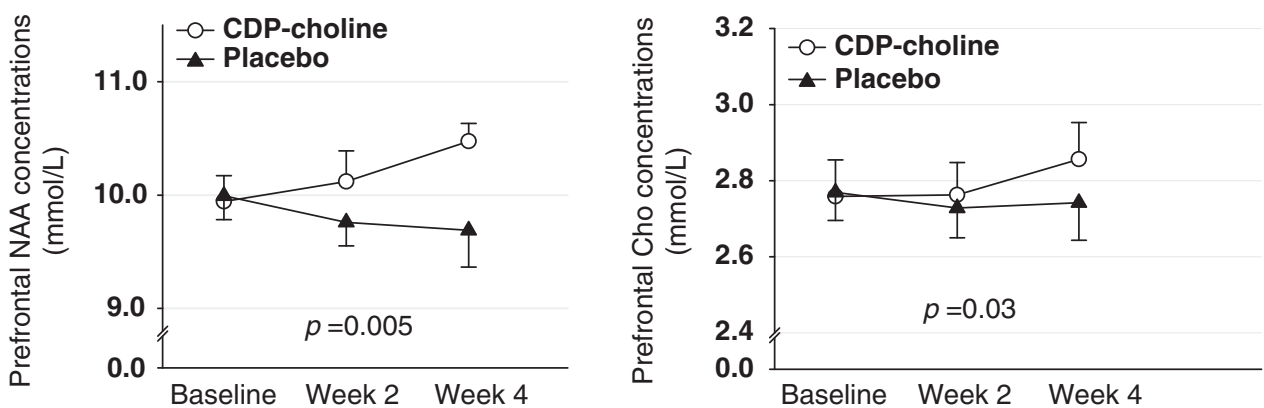

Figure 2 Changes in cerebral NAA and Cho levels over the 4-week treatment period in CDP-choline $(n=16)$ and placebo $(n=15)$-treated MAdependent patients. Cerebral NAA and Cho levels were corrected values. The $p$-values in each figure were calculated by F-test for the interaction between group and time in the GEE model. Error bars represent the standard errors. CDP-choline, cytidine-5'-diphosphate choline; MA, methamphetamine; NAA, $\mathrm{N}$-acetyl-aspartate/ $\mathrm{N}$-acetyl-aspartyl glutamate; Cho, phosphocholine/glycerophosphocholine; CSF, cerebrospinal fluid; GEE, generalized estimating equation.

covariate (NAA levels, $z=2.60, p=0.009$; Cho levels, $z=2.03, p=0.04)$. There were no significant interaction effects of 'treatment groups' and 'time' on changes in other prefrontal metabolite levels including creatine or myoinositol (Supplementary Table 1).

\section{Relationship Between Magnitude of Change in NAA Levels and Clinical Outcome}

In an effort to examine whether prefrontal NAA and Cho changes were associated with clinical outcome, the relationship between prefrontal NAA or Cho level changes over the 4-week period and the total number of negative urine results was assessed. In the CDP-choline-treated group, percentage changes in prefrontal NAA levels from baseline to 4 -week end point were positively correlated with the total number of negative urine results $(\rho=0.62, p=0.032)$ (Figure 3). However, the placebo-treated group did not show a significant relationship between percentage changes in prefrontal NAA levels and the number of total negative urine results $(\rho=-0.50, p=0.17)$. There was no significant association between percentage changes in prefrontal Cho levels and the total number of the negative urine results both in the CDP-choline $(\rho=0.28, p=0.37)$ and the placebo-treated $(\rho=-0.03, p=0.95)$ groups.

\section{Adverse Events}

CDP-choline was relatively well tolerated in MA-dependent subjects. In the CDP-choline group, cumulative adverse events included gastrointestinal discomfort (25.0\%), headache $(25.0 \%)$, insomnia $(18.8 \%)$, myalgia $(18.8 \%)$, restlessness (6.3\%), fatigue (6.3\%), and tremor (6.3\%). Adverse events of subjects assigned to the placebo group included gastrointestinal discomfort $(20.0 \%)$, headache $(26.7 \%)$, insomnia $(20.0 \%)$, myalgia $(20.0 \%)$, restlessness $(13.3 \%)$, and dizziness $(6.7 \%)$. No serious adverse events were noted in either of the treatment groups. The profiles and frequency of the adverse events did not differ between the two groups.

\section{DISCUSSION}

Our most notable finding is that CDP-choline treatment increases prefrontal NAA and Cho levels in MA-dependent

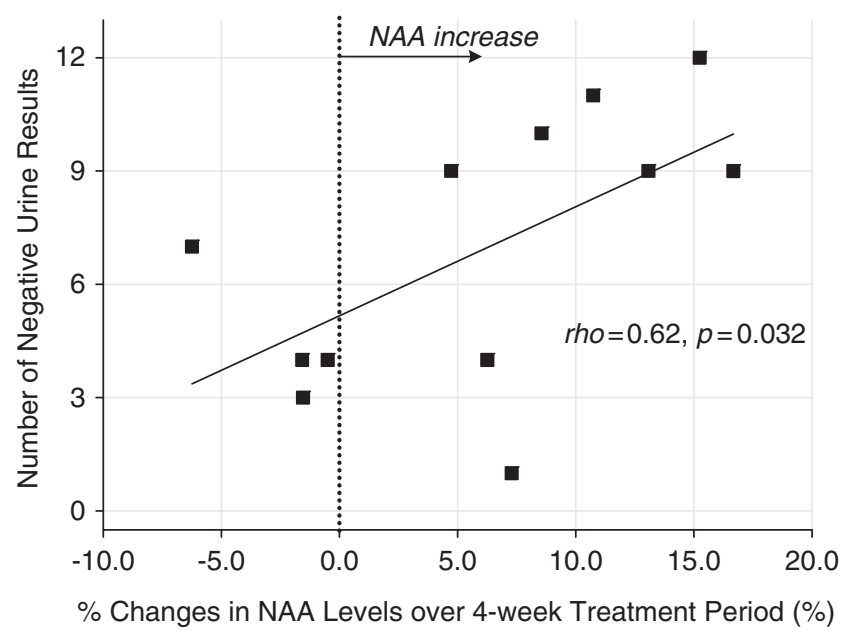

Figure 3 Relationships between percentage changes in prefrontal NAA levels over the 4-week treatment period and the total number of negative urine results in CDP-choline-treated MA-dependent patients. Scatter plots were depicted based on 12 CDP-choline-treated patients whose second follow-up MRS scan at 4 weeks was available. CDP-choline, cytidine-5'diphosphate choline; MA, methamphetamine; NAA, N-acetyl-aspartate/ $N$ acetyl-aspartyl glutamate.

patients and that prefrontal NAA levels were associated with a higher number of negative urine results.

CDP-choline has been reported to be effective in several neurological disorders including cerebral vascular disease, hypoxia, traumatic brain injury, and Parkinson disease (reviewed in Adibhatla and Hatcher, 2005). Preclinical studies have also suggested the neuroprotective effects of CDP-choline on improving learning and memory in the aging model (reviewed in Secades and Lorenzo, 2006). The recovery of cerebral cellular membrane structures and normalization of phospholipid metabolisms have been hypothesized to be mechanisms of neuroprotective action for CDP-choline (Adibhatla and Hatcher, 2005; Secades and Lorenzo, 2006).

Repair of membranes may directly impact the synaptic transmissions and neurotransmitter levels, including dopamine or serotonin (Agut et al, 1984; Martinet et al, 1978, 1979; Saligaut et al, 1985). Along with these mechanisms, CDP-choline has been reported to protect dopaminergic neurons (Barrachina et al, 2003; Radad et al, 2007). This activity of CDP-choline on the dopamine system may also 
be associated with its beneficial effects for psychostimulant dependence (Renshaw et al, 1999).

Earlier MRS studies have reported lower cerebral levels of NAA, a putative marker of neuroplasticity, in MAdependent patients (Chang et al, 2005; Ernst et al, 2000; Nordahl et al, 2002, 2005; Salo et al, 2007; Smith et al, 2001; Sung et al, 2007) and a potential reversal of reduced NAA levels with long-term abstinence (Sung et al, 2007). Normalization of low cerebral NAA levels with treatment or symptom improvement has been reported in several neurological disorders including multiple sclerosis, traumatic brain injury, Parkinson's disease, and HIV-related encephalopathy (Davie et al, 1994; De Stefano et al, 1995; Ellis et al, 1997; Holshouser et al, 1995; Mathew et al, 2008; Vion-Dury et al, 1995). Reduced NAA levels have also been shown to be normalized in response to at least 4 weeks of treatment with psychotropic medications such as lithium and olanzapine in bipolar disorder and schizophrenia, respectively, all of which have been considered to have neurotrophic effects (Bertolino et al, 2001; Moore et al, 2000). Taken together, robust increases in prefrontal NAA levels after CDP-choline treatment suggest that CDP-choline may restore neuronal viability.

Increased NAA levels with CDP-choline treatment may also be explained by restoration of mitochondrial damage in subjects with MA dependence. Mitochondrial dysfunction has been proposed as one of the important mechanisms for MA neurotoxicity (Davidson et al, 2001; Tian et al, 2009; Quinton and Yamamoto, 2006; Brown and Yamamoto, 2003). Given that NAA is mainly synthesized in mitochondria (Patel and Clark, 1979; Truckenmiller et al, 1985) and that synthesis of NAA requires an energy-dependent step (Patel and Clark, 1979), lower NAA levels have been, in part, considered as a putative marker for mitochondrial dysfunction (Clark, 1998). CDP-choline may boost mitochondrial energy production by diminishing the disruption of cerebral mitochondrial lipid metabolism seen in pathological conditions such as hypoxia (Alberghina et al, 1981).

It is potentially noteworthy that increases in prefrontal NAA levels were associated with clinical improvement of less MA use only in the CDP-choline-treated group. However, the fact that there was no significant difference in clinical outcome between the CDP-choline and placebo groups in this study limits further interpretation of this relationship.

We also found that prefrontal Cho levels also increased with CDP-choline treatment. Considering that exogenously administered CDP-choline is metabolized into cytidine and choline and absorbed into the brain (Weiss, 1995; Wurtman et al, 2000), this was not unexpected.

Chos detected by proton MRS are mainly composed of PC and GPC (Bluml et al, 1999), whereas free choline and acetylcholine contribute to $<5 \%$ of cerebral Cho resonance (Boulanger et al, 2000). Consequently, increased Cho signal in our CDP-choline-treated patients are likely to represent increases in cerebral PC and GPC levels. This potentially reflects increased phospholipid membrane turnover. This finding is in accord with earlier proton and phosphorous MRS studies, which examined the effects of oral CDPcholine administration on brain Cho levels (Babb et al, 2002; Silveri et al, 2008).
In this study, a daily intake of $2000 \mathrm{mg}$ of CDP-choline seems to be safe and well tolerated in MA-dependent subjects. The most common side effects of CDP-choline were transient gastrointestinal discomforts (25\%). These included nausea, indigestion, abdominal pain, and diarrhea. Some subjects experienced a light headache $(25 \%)$ as a side effect. The frequency of these side effects, however, did not differ from that of the placebo group. There were no serious adverse events or related drop-outs in CDP-choline-treated patients. This safety profile is comparable with that found in earlier clinical studies of healthy volunteers or patients with various neurological disorders who have taken 500-2000 mg dosage of CDP-choline (Clark et al, 2001; Secades and Lorenzo, 2006).

In this study, there was no difference in the total number of negative urine results between groups. The absence of CDP-choline's efficacy in this study may stem from a number of factors including a relatively small sample size, a short trial period, and high attrition rates.

Although smoking is the major route of MA administration in the United States (Drug Enforcement Administration, 2007), all of our subjects were IV MA abusers. The fact that abuse potential of MA is higher in IV administration than in other routes (Murray, 1998) may have contributed to a smaller effect size of treatment efficacy than expected. This would be another potential cause for CDP-choline's lack of clinical efficacy.

The primary limitation of this study may be its short treatment duration. We could not confirm whether the clear effects of CDP-choline on NAA levels would be confined to an earlier treatment period or maintained for a longer period of time. Considering that efficient pharmacological treatments for MA dependence have not been available to date (Meredith et al, 2005; Rawson et al, 2000; Vocci and Appel, 2007), studies with a larger sample size and a longer treatment period on examining CDP-choline's efficacy in MA dependence are warranted.

Although individual and family counseling was given to all subjects, psychosocial approaches specific to MA dependence, such as the matrix model or cognitive behavioral therapy (CBT), were not included as a treatment protocol. Given that interplay and potential synergic effects between certain types of psychosocial approaches and pharmacotherapy have been reported in patients with cocaine dependence (Poling et al, 2006) and alcohol dependence (O'Malley et al, 1992), treatment protocol without specific psychosocial approaches would be another limitation of this study.

The results from the correlation analyses between NAA levels and the number of negative urine results in CDPcholine-treated subjects may be dependent on the results from a highly abstinent subgroup. Although a nonparametric statistical analysis method was used in assessing this relationship, when interpreting the results, it should be considered that the study sample was small in size and, therefore, slightly skewed.

In conclusion, this study suggests that oral CDP-choline administration is associated with increases in prefrontal NAA levels and has a potential clinical efficacy in treating MA dependence through its neuroprotective effects. 


\section{ACKNOWLEDGEMENTS}

This study was supported in part by grants from the NIDA (1R01 DA024070-01A1, Drs Lyoo and Renshaw; 5 R01 DA 14178-05, Dr Renshaw), from the NIH (7K24DA015116, Dr Renshaw; 5K05-DA000343-12, Dr Lukas), from the Korean Ministry of Education, Science and Technology, (2009K001272, Dr Lyoo; Basic Science Research Program 20090066915, Dr Yoon), and from Seoul National University Hospital (03-2008-006-0, Dr Lyoo).

\section{DISCLOSURE}

Dr Lyoo has received research support from Eli Lilly, AstraZeneca, GSK, and Lundbeck. He has no other potential conflicts of interest to disclose. Dr Renshaw is a consultant for Novartis, Roche, and Kyowa Hakko and has research support from Roche and GSK. Drs Renshaw and Lukas are inventors on two patents that describe the use of CDPcholine for the treatment of stimulant dependence. These patents have been assigned to McLean Hospital. Neither Dr Renshaw nor Dr Lukas directly evaluated any of the subjects who were enrolled in the trial. Drs Yoon and Kim have no conflict of interest to declare.

\section{REFERENCES}

Adibhatla RM, Hatcher JF (2005). Cytidine 5'-diphosphocholine (CDP-choline) in stroke and other CNS disorders. Neurochem Res 30: 15-23.

Agut J, Coviella IL, Wurtman RJ (1984). Cytidine $\left(5^{\prime}\right)$ diphosphocholine enhances the ability of haloperidol to increase dopamine metabolites in the striatum of the rat and to diminish stereotyped behavior induced by apomorphine. Neuropharmacology 23: 1403-1406.

Alberghina M, Viola M, Serra I, Mistretta A, Giuffrida AM (1981). Effect of CDP-choline on the biosynthesis of phospholipids in brain regions during hypoxic treatment. J Neurosci Res 6: 421-433.

Araki W, Wurtman RJ (1998). How is membrane phospholipid biosynthesis controlled in neural tissues? J Neurosci Res 51: 667-674.

Babb SM, Wald LL, Cohen BM, Villafuerte RA, Gruber SA, Yurgelun-Todd DA et al (2002). Chronic citicoline increases phosphodiesters in the brains of healthy older subjects: an in vivo phosphorus magnetic resonance spectroscopy study. Psychopharmacology (Berl) 161: 248-254.

Bae SC, Lyoo IK, Sung YH, Yoo J, Chung A, Yoon SJ et al (2006). Increased white matter hyperintensities in male methamphetamine abusers. Drug Alcohol Depend 81: 83-88.

Barker PB, Soher BJ, Blackband SJ, Chatham JC, Mathews VP, Bryan RN (1993). Quantitation of proton NMR spectra of the human brain using tissue water as an internal concentration reference. NMR Biomed 6: 89-94.

Barrachina M, Dominguez I, Ambrosio S, Secades J, Lozano R, Ferrer I (2003). Neuroprotective effect of citicoline in 6-hydroxydopamine-lesioned rats and in 6-hydroxydopaminetreated SH-SY5Y human neuroblastoma cells. J Neurol Sci 215: 105-110.

Barrachina M, Secades J, Lozano R, Gomez-Santos C, Ambrosio S, Ferrer I (2002). Citicoline increases glutathione redox ratio and reduces caspase-3 activation and cell death in staurosporinetreated SH-SY5Y human neuroblastoma cells. Brain Res 957: 84-90.
Berman S, O’Neill J, Fears S, Bartzokis G, London ED (2008). Abuse of amphetamines and structural abnormalities in the brain. Ann N Y Acad Sci 1141: 195-220.

Bertolino A, Callicott JH, Mattay VS, Weidenhammer KM, Rakow $\mathrm{R}$, Egan MF et al (2001). The effect of treatment with antipsychotic drugs on brain $\mathrm{N}$-acetylaspartate measures in patients with schizophrenia. Biol Psychiatry 49: 39-46.

Bluml S, Seymour KJ, Ross BD (1999). Developmental changes in choline- and ethanolamine-containing compounds measured with proton-decoupled (31)P MRS in in vivo human brain. Magn Reson Med 42: 643-654.

Boulanger Y, Labelle M, Khiat A (2000). Role of phospholipase $A(2)$ on the variations of the choline signal intensity observed by $1 \mathrm{H}$ magnetic resonance spectroscopy in brain diseases. Brain Res Brain Res Rev 33: 380-389.

Brown ES, Gorman AR, Hynan LS (2007). A randomized, placebocontrolled trial of citicoline add-on therapy in outpatients with bipolar disorder and cocaine dependence. J Clin Psychopharmacol 27: 498-502.

Brown JM, Yamamoto BK (2003). Effects of amphetamines on mitochondrial function: role of free radicals and oxidative stress. Pharmacol Ther 99: 45-53.

Bustillo JR, Rowland LM, Jung R, Brooks WM, Qualls C, Hammond $\mathrm{R}$ et al (2008). Proton magnetic resonance spectroscopy during initial treatment with antipsychotic medication in schizophrenia. Neuropsychopharmacology 33: 2456-2466.

Chang L, Ernst T, Speck O, Grob CS (2005). Additive effects of HIV and chronic methamphetamine use on brain metabolite abnormalities. Am J Psychiatry 162: 361-369.

Christensen JD, Kaufman MJ, Levin JM, Mendelson JH, Holman BL, Cohen BM et al (1996). Abnormal cerebral metabolism in polydrug abusers during early withdrawal: a 31P MR spectroscopy study. Magn Reson Med 35: 658-663.

Chung A, Lyoo IK, Kim SJ, Hwang J, Bae SC, Sung YH et al (2007). Decreased frontal white-matter integrity in abstinent methamphetamine abusers. Int J Neuropsychopharmacol 10: 765-775.

Clark JB (1998). N-acetyl aspartate: a marker for neuronal loss or mitochondrial dysfunction. Dev Neurosci 20: 271-276.

Clark WM, Wechsler LR, Sabounjian LA, Schwiderski UE (2001). A phase III randomized efficacy trial of $2000 \mathrm{mg}$ citicoline in acute ischemic stroke patients. Neurology 57: 1595-1602.

Clement JM, Kent C (1999). CTP:phosphocholine cytidylyltransferase: insights into regulatory mechanisms and novel functions. Biochem Biophys Res Commun 257: 643-650.

Davidson C, Gow AJ, Lee TH, Ellinwood EH (2001). Methamphetamine neurotoxicity: necrotic and apoptotic mechanisms and relevance to human abuse and treatment. Brain Res Brain Res Rev 36: 1-22.

Davie CA, Hawkins CP, Barker GJ, Brennan A, Tofts PS, Miller DH et al (1994). Serial proton magnetic resonance spectroscopy in acute multiple sclerosis lesions. Brain 117(Pt 1): 49-58.

De Stefano N, Matthews PM, Arnold DL (1995). Reversible decreases in N-acetylaspartate after acute brain injury. Magn Reson Med 34: 721-727.

Deicken RF, Zhou L, Schuff N, Fein G, Weiner MW (1998). Hippocampal neuronal dysfunction in schizophrenia as measured by proton magnetic resonance spectroscopy. Biol Psychiatry 43: 483-488.

Drug Enforcement Administration (2007). National Drug Threat Assessment. Available at http://www.usdoj.gov/ndic/pubs21/ 21137/meth.htm, accessed 22 December 2008.

Drug Enforcement Administration (2008). National Drug Threat Assessment. Available at http://www.usdoj.gov/ndic/pubs25/ 25921/, accessed 22 December 2008.

Ellis CM, Lemmens G, Williams SC, Simmons A, Dawson J, Leigh $\mathrm{PN}$ et al (1997). Changes in putamen $\mathrm{N}$-acetylaspartate and choline ratios in untreated and levodopa-treated Parkinson's 
disease: a proton magnetic resonance spectroscopy study. Neurology 49: 438-444.

Ernst T, Chang L, Leonido-Yee M, Speck O (2000). Evidence for long-term neurotoxicity associated with methamphetamine abuse: a 1H MRS study. Neurology 54: 1344-1349.

First MB, Spitzer RL, Gibbon M, Williams JBW (2002). Structural Clinical Interview for DSM-IV-TR, Research Version, Non-patient Edition. Biometrics Research, New York State Psychiatric Institute: New York.

Grohman K, Fals-Stewart W, Donnelly K (2006). Improving treatment response of cognitively impaired veterans with neuropsychological rehabilitation. Brain Cogn 60: 203-204.

Ham BJ, Chey J, Yoon SJ, Sung Y, Jeong DU, Ju Kim S et al (2007). Decreased $\mathrm{N}$-acetyl-aspartate levels in anterior cingulate and hippocampus in subjects with post-traumatic stress disorder: a proton magnetic resonance spectroscopy study. Eur J Neurosci 25: 324-329.

Hamilton M (1960). A rating scale for depression. J Neurol Neurosurg Psychiatry 23: 56-62.

Holshouser BA, Komu M, Moller HE, Zijlmans J, Kolem H, Hinshaw Jr DB et al (1995). Localized proton NMR spectroscopy in the striatum of patients with idiopathic Parkinson's disease: a multicenter pilot study. Magn Reson Med 33: 589-594.

Hussain T, Lokhandwala MF (1997). Dopamine-1 receptor G-protein coupling and the involvement of phospholipase A2 in dopamine-1 receptor mediated cellular signaling mechanisms in the proximal tubules of SHR. Clin Exp Hypertens 19: 131-140.

Hwang J, Lyoo IK, Kim SJ, Sung YH, Bae S, Cho SN et al (2006). Decreased cerebral blood flow of the right anterior cingulate cortex in long-term and short-term abstinent methamphetamine users. Drug Alcohol Depend 82: 177-181.

Kennedy EP, Weiss SB (1956). The function of cytidine coenzymes in the biosynthesis of phospholipides. J Biol Chem 222: 193-214.

Kim SJ, Lyoo IK, Hwang J, Chung A, Hoon Sung Y, Kim J et al (2006). Prefrontal grey-matter changes in short-term and longterm abstinent methamphetamine abusers. Int J Neuropsychopharmacol 9: 221-228.

Kim SJ, Lyoo IK, Hwang J, Sung YH, Lee HY, Lee DS et al (2005). Frontal glucose hypometabolism in abstinent methamphetamine users. Neuropsychopharmacology 30: 1383-1391.

Lee NK, Rawson RA (2008). A systematic review of cognitive and behavioural therapies for methamphetamine dependence. Drug Alcohol Rev 27: 309-317.

Lukas SE, Kouri EM, Rhee C, Madrid A, Renshaw PF (2001). Effects of short-term citicoline treatment on acute cocaine intoxication and cardiovascular effects. Psychopharmacology (Berl) 157: 163-167.

MacKay S, Meyerhoff DJ, Dillon WP, Weiner MW, Fein G (1993). Alteration of brain phospholipid metabolites in cocainedependent polysubstance abusers. Biol Psychiatry 34: 261-264.

Martinet M, Fonlupt P, Pacheco H (1978). Interaction of CDPcholine with synaptosomal transport of biogenic amines and their precursors in vitro and in vivo in the rat corpus striatum. Experientia 34: 1197-1199.

Martinet M, Fonlupt P, Pacheco H (1979). Effects of cytidine-5' diphosphocholine on norepinephrine, dopamine and serotonin synthesis in various regions of the rat brain. Arch Int Pharmacodyn Ther 239: 52-61.

Mathew SJ, Price RB, Mao X, Smith EL, Coplan JD, Charney DS et al (2008). Hippocampal N-acetylaspartate concentration and response to riluzole in generalized anxiety disorder. Biol Psychiatry 63: 891-898.

McAllister G, Knowles MR, Patel S, Marwood R, Emms F, Seabrook GR et al (1993). Characterisation of a chimeric hD3/D2 dopamine receptor expressed in CHO cells. FEBS Lett 324: 81-86.

McLean MA, Woermann FG, Simister RJ, Barker GJ, Duncan JS (2001). In vivo short echo time $1 \mathrm{H}$-magnetic resonance spectroscopic imaging (MRSI) of the temporal lobes. Neuroimage 14: 501-509.
Meredith CW, Jaffe C, Ang-Lee K, Saxon AJ (2005). Implications of chronic methamphetamine use: a literature review. Harv Rev Psychiatry 13: 141-154.

Moore GJ, Bebchuk JM, Hasanat K, Chen G, Seraji-Bozorgzad N, Wilds IB et al (2000). Lithium increases $\mathrm{N}$-acetyl-aspartate in the human brain: in vivo evidence in support of bcl-2's neurotrophic effects? Biol Psychiatry 48: 1-8.

Murray JB (1998). Psychophysiological aspects of amphetaminemethamphetamine abuse. J Psychol 132: 227-237.

National Survey on Drug Use and Health (NSDUH) (2005). Results from the 2005 NSUDH. Available at http://www.oas.samhsa.gov/ p0000016.htm\#2k7, accessed 22 December 2008.

Nordahl TE, Salo R, Natsuaki Y, Galloway GP, Waters C, Moore CD et al (2005). Methamphetamine users in sustained abstinence: a proton magnetic resonance spectroscopy study. Arch Gen Psychiatry 62: 444-452.

Nordahl TE, Salo R, Possin K, Gibson DR, Flynn N, Leamon M et al (2002). Low N-acetyl-aspartate and high choline in the anterior cingulum of recently abstinent methamphetamine-dependent subjects: a preliminary proton MRS study. Magnetic resonance spectroscopy. Psychiatry Res 116: 43-52.

O'Malley SS, Jaffe AJ, Chang G, Schottenfeld RS, Meyer RE, Rounsaville B (1992). Naltrexone and coping skills therapy for alcohol dependence. A controlled study. Arch Gen Psychiatry 49: 881-887.

Patel TB, Clark JB (1979). Synthesis of N-acetyl-L-aspartate by rat brain mitochondria and its involvement in mitochondrial/ cytosolic carbon transport. Biochem J 184: 539-546.

Poling J, Oliveto A, Petry N, Sofuoglu M, Gonsai K, Gonzalez G et al (2006). Six-month trial of bupropion with contingency management for cocaine dependence in a methadone-maintained population. Arch Gen Psychiatry 63: 219-228.

Provencher SW (2001). Automatic quantitation of localized in vivo $1 \mathrm{H}$ spectra with LCModel. NMR Biomed 14: 260-264.

Provencher SW (2008). LCModel User's Manual, version 6.2, available at http://s-provencher.com/pages/lcm-manual.shtml.

Quinton MS, Yamamoto BK (2006). Causes and consequences of methamphetamine and MDMA toxicity. AAPS J 8: E337-E347.

Radad K, Gille G, Xiaojing J, Durany N, Rausch WD (2007). CDPcholine reduces dopaminergic cell loss induced by $\mathrm{MPP}(+)$ and glutamate in primary mesencephalic cell culture. Int J Neurosci 117: 985-998.

Rawson RA, McCann MJ, Hasson AJ, Ling W (2000). Addiction pharmacotherapy 2000: new options, new challenges. J Psychoactive Drugs 32: 371-378.

Reid MS, Hsu K, Tolliver BK, Crawford CA, Berger SP (1996). Evidence for the involvement of phospholipase A2 mechanisms in the development of stimulant sensitization. J Pharmacol Exp Ther 276: 1244-1256.

Renshaw PF, Daniels S, Lundahl LH, Rogers V, Lukas SE (1999). Short-term treatment with citicoline (CDP-choline) attenuates some measures of craving in cocaine-dependent subjects: a preliminary report. Psychopharmacology (Berl) 142: $132-138$

Ross BM, Moszczynska A, Kalasinsky K, Kish SJ (1996). Phospholipase A2 activity is selectively decreased in the striatum of chronic cocaine users. J Neurochem 67: 2620-2623.

Ross BM, Moszczynska A, Peretti FJ, Adams V, Schmunk GA, Kalasinsky KS et al (2002). Decreased activity of brain phospholipid metabolic enzymes in human users of cocaine and methamphetamine. Drug Alcohol Depend 67: 73-79.

Ross BM, Turenne SD (2002). Chronic cocaine administration reduces phospholipase $\mathrm{A}(2)$ activity in rat brain striatum. Prostaglandins Leukot Essent Fatty Acids 66: 479-483.

Saligaut C, Daoust M, Chadelaud M, Moore N, Chretien P, Boismare F (1985). Oxotremorine-induced cholinergic syndrome: modifications by levodopa and/or oral cytidine diphosphocholine. Methods Find Exp Clin Pharmacol 7: 5-8. 
Salo R, Nordahl TE, Natsuaki Y, Leamon MH, Galloway GP, Waters C et al (2007). Attentional control and brain metabolite levels in methamphetamine abusers. Biol Psychiatry 61: 1272-1280.

Scott JC, Woods SP, Matt GE, Meyer RA, Heaton RK, Atkinson JH et al (2007). Neurocognitive effects of methamphetamine: a critical review and meta-analysis. Neuropsychol Rev 17: 275-297.

Secades JJ, Lorenzo JL (2006). Citicoline: pharmacological and clinical review, 2006 update. Methods Find Exp Clin Pharmacol 28(Suppl B): 1-56.

Shearer J (2007). Psychosocial approaches to psychostimulant dependence: a systematic review. J Subst Abuse Treat 32: 41-52.

Silveri MM, Dikan J, Ross AJ, Jensen JE, Kamiya T, Kawada Y et al (2008). Citicoline enhances frontal lobe bioenergetics as measured by phosphorus magnetic resonance spectroscopy. NMR Biomed 21: 1066-1075.

Smith LM, Chang L, Yonekura ML, Grob C, Osborn D, Ernst T (2001). Brain proton magnetic resonance spectroscopy in children exposed to methamphetamine in utero. Neurology 57: 255-260.

Sung YH, Cho SC, Hwang J, Kim SJ, Kim H, Bae S et al (2007). Relationship between $\mathrm{N}$-acetyl-aspartate in gray and white matter of abstinent methamphetamine abusers and their history of drug abuse: a proton magnetic resonance spectroscopy study. Drug Alcohol Depend 88: 28-35.

Tian C, Murrin LC, Zheng JC (2009). Mitochondrial fragmentation is involved in methamphetamine-induced cell death in rat hippocampal neural progenitor cells. PLoS One 4: e5546.

Truckenmiller ME, Namboodiri MA, Brownstein MJ, Neale JH (1985). N-Acetylation of L-aspartate in the nervous system: differential distribution of a specific enzyme. J Neurochem 45: $1658-1662$.
Vial D, Piomelli D (1995). Dopamine D2 receptors potentiate arachidonate release via activation of cytosolic, arachidonatespecific phospholipase A2. J Neurochem 64: 2765-2772.

Vion-Dury J, Nicoli F, Salvan AM, Confort-Gouny S, Dhiver C, Cozzone PJ (1995). Reversal of brain metabolic alterations with zidovudine detected by proton localised magnetic resonance spectroscopy. Lancet 345: 60-61.

Vocci FJ, Appel NM (2007). Approaches to the development of medications for the treatment of methamphetamine dependence. Addiction 102(Suppl 1): 96-106.

Wang AM, Suojanen JN, Colucci VM, Rumbaugh CL, Hollenberg NK (1990). Cocaine- and methamphetamine-induced acute cerebral vasospasm: an angiographic study in rabbits. Am J Neuroradiol 11: 1141-1146.

Weiss GB (1995). Metabolism and actions of CDP-choline as an endogenous compound and administered exogenously as citicoline. Life Sci 56: 637-660.

Winsberg ME, Sachs N, Tate DL, Adalsteinsson E, Spielman D, Ketter TA (2000). Decreased dorsolateral prefrontal N-acetyl aspartate in bipolar disorder. Biol Psychiatry 47: 475-481.

Wurtman RJ, Regan M, Ulus I, Yu L (2000). Effect of oral CDPcholine on plasma choline and uridine levels in humans. Biochem Pharmacol 60: 989-992.

Yoon SJ, Lyoo IK, Haws C, Kim TS, Cohen BM, Renshaw PF (2009). Decreased glutamate/glutamine levels may mediate cytidine's efficacy in treating bipolar depression: a longitudinal proton magnetic resonance spectroscopy study. Neuropsychopharmacol 34: $1810-1818$.

Zeger SL, Liang KY (1986). Longitudinal data analysis for discrete and continuous outcomes. Biometrics 42: 121-130.

Supplementary Information accompanies the paper on the Neuropsychopharmacology website (http://www.nature.com/npp) 